\title{
Cytokines and the lung
}

\author{
G.B. Toews
}

Cytokines and the lung. G.B. Toews. (C)ERS Journals Ltd 2001.

ABSTRACT: Cytokines are signal molecules that induce movement, differentiation, growth and death of many cell types. Cytokines generate these effects through interactions with receptors, which relay a signal into the cell triggering a response.

Cytokine-receptor interactions are promiscuous; a combining site of any receptor can bind many ligands. Promiscuity allows for the generation of agonists, alternative ligands that activate a receptor in a way similar to the normal ligands and antagonists, ligands that bind to a receptor, but neutralize the effects of an agonist. Cytokinereceptor interactions induce many diverse (pleiotropic) effects. Cytokine-receptor interactions are redundant; several cytokines can perform the same function.

Mammalian hosts use cytokines to maintain homeostasis and to provide signals crucial to host responses to invading microbes and other injurious agents. Cytokines are the molecular messages, which: 1) initiate and amplify inflammatory and immune responses by recruiting and activating cells; 2 ) regulate the activation and differentiation of T- and B-lymphocytes, whose functions are crucial to specific cell-mediated immunity; and 3) initiate and regulate local repair processes critical to the resolution of inflammatory responses.

Further studies of cytokines and their receptors should provide a framework for therapeutic interventions in patients with dysregulated inflammatory responses. Eur Respir J 2001; 18: Suppl. 34, 3s-17s.

Division of Pulmonary and Critical Care Medicine, University of Michigan Hospital, Ann Arbor, MI, USA.

Correspondence: G.B. Toews

Division of Pulmonary and

Critical Care Medicine

University of Michigan Hospital

Ann Arbor

MI

USA

Fax: 17347644556

Keywords:

Received: July 312001

Accepted after revision August 12001
A review of cytokines and the lung is a daunting task. The scope of cytokine biology is immense since these molecules have wide-ranging biological effects. More than 190,000 citations that index cytokines have been published in the last decade and $>1,800$ cytokine manuscripts were published in the past month. A definition of "cytokines" is not simple; most textbooks and reviews do not provide such a definition. For the purpose of this review, cytokines will be defined as a diverse group of protein signal molecules that are produced by a wide variety of cells. Cytokines influence or activate adjacent cell movement, differentiation, growth and death. Cytokines generate these effects through interactions with receptors already present in low density on the cell surface or through upregulation of new receptors. Cytokine receptors relay a signal into the cell triggering a response. Regulation of receptor expression is as important as regulation of cytokine production if pulmonary homeostasis is to be maintained. Networks of cytokines act cooperatively to control normal physiological activity and disease-related threats to homeostasis. Furthermore, the composition of the cytokine milieu changes as disease processes progress and during resolution, remodelling and healing responses.

\section{Characteristics of cytokine-receptor interactions}

\section{Promiscuity}

The binding of cytokine ligands to cytokine receptors is promiscuous. A binding site of a receptor can bind many ligands and a ligand can bind several receptors. Molecular specificity hinges on the array of noncovalent bonds formed at the points of contact between the ligand and receptor. Sensitivity of ligand binding to ligand concentration allows the quantitation of binding affinity, the energy of binding between the receptor and the ligand. If the noncovalent forces of attraction between receptor and ligand are great, dissociation is unlikely even at a low concentration of ligand and the binding site of the receptor will be occupied by the ligand. Conversely, low-affinity interactions lead to high rates of ligand dissociation. A high concentration of ligand molecule will be necessary to maintain occupancy. While this degeneracy is disappointing at first glance, the intrinsic degeneracy of cytokine-receptor interactions has important biological consequences. Biological recognition and regulation occurs when molecules and receptors fit and bind for a moment in time. Ligand-receptor interactions, like an effective handshake, are reversible. This ligand-receptor plasticity underlies the bulk of pharmacological approaches to this system of biological regulators. Agonists are alternative ligands that can activate a receptor in a way similar to that of the natural ligand. Antagonists are ligands that bind physically to the receptor, but rather than activating the receptor, neutralize the effects of an agonist. An antagonist can function as a blocking or competing molecule.

\section{Pleiotropia}

A single cytokine molecule can produce many diverse effects. Pleiotropia does not refer to the 
alternative reaction states of a molecule but to a true diversity of function. Cytokines cause effects by activating genes. Interferon gamma (IFN- $\gamma$ ) activates $>200$ different genes [1]. Each of the 200 genes is more or less pleiotropic themselves; each gene might express itself differently in different target cells. A single molecule such as IFN- $\gamma$ is pleiotropic at the most basic causal level.

\section{Redundancy}

Redundancy describes situations in which several agents perform the same action. Although the agents are not identical, they are redundant to the degree to which they may replace one another functionally. Chemokines are a particularly redundant cytokine system [2]. Redundancy is complicated by the fact that different agents can produce some of the same effects as well as different ones. Tumour necrosis factor alpha $(\mathrm{TNF}-\alpha)$ and IFN- $\gamma$ partially overlap in their immune effects; both cytokines are crucial to protective immunity, but each cytokine produces effects that the other does not. Redundancy can be defined as the partially overlapping pleiotropisms of diverse agents.

\section{Polyspeirism}

Polyspeirism is a particular type of redundancy. Polyspeirism defines a circumstance in which multiple cytokines are produced in a redundant way by a single cell concomitantly in response to the same stimulus. Polyspeirism is particularly striking for mononuclear phagocytes and endothelial cells exposed to bacterial products. In response to bacterial products, these cells produce virtually all CC chemokines, fractalkine (CX3C) and some CXC chemokines. This characteristic provides a robustness for certain necessary functions such as phagocyte recruitment. Because of the robustness of the response, variations in the quantity of any chemokine(s) or receptor(s) would have bearable consequences for basal trafficking of phagocytes.

\section{Cytokines and the lung}

Cytokines, broadly defined, are involved in normal regulation of all physiological processes. The role that cytokines play in the regulation and modulation of immunological and inflammatory processes is striking. The lung is particularly dependent on tightly regulated immunological and inflammatory processes since it is exposed to a large and varied burden of infectious agents as well as a diverse group of noxious gases and particulates during the process of gas exchange. The lung defends itself from these injurious agents by deploying cytokine-regulated host defence mechanisms wherever it interfaces with the external environment [3]. This review focuses on the cytokines present at the interface of infectious and inflammatory diseases. Cytokines present in the lung clearly regulate both the initiation and maintenance of immune and inflammatory responses. Cytokines select the type of response generated and the effector mechanisms to be utilized. Cytokines are the intercellular words that provided instructions in cell networks, which provide three crucial functions. First, these cytokinecontrolled networks of cells must "classify" the universe into injurious and innocuous agents. Second, the network must "determine" whether to respond or ignore the substance (activation versus tolerance). Third, it must "regulate" the recruited and activated cells [4-7]. Cytokines are the molecular signals for communication between cells of the immune system and the systemic mediators or the host response to infection. Cytokines: 1) initiate and amplify inflammation; 2) induce T-cell independent macrophage activation; 3) regulate dendritic cell maturation and differentiation; 4) regulate T-cell activation and activation and differentiation; 5) modify connective tissue structures; and 6) regulate blood vessel growth.

\section{Mechanisms of innate immune recognition}

The immune system has traditionally been divided into innate and adaptive components $[4,7,8]$. Innate immunity is an ancient system of host defence that preceded the development of specific immunity. All multicellular organisms have some form of innate immune defence. The main distinction between the innate and specific immune systems lies in the receptors and mechanisms used for immune recognition. Innate immune recognition is mediated by germ line-encoded receptors. Each receptor has been genetically predetermined to have defined specificities for infectious micro-organisms by natural selection.

Microbial recognition is problematic because of their high mutation rate and their molecular heterogeneity. Eukaryotic organisms must limit the number of genes they commit to microbial recognition. The innate immune response has evolved to recognize a few, highly conserved structures present in large groups of micro-organisms $[5,6]$. The innate immune system utilizes receptors thought to number in the hundreds to accomplish this task. The receptors recognize molecular patterns rather than particular structures and accordingly have been termed pathogen recognition receptors (PRR) [5-9]. The patterns recognized by PRR have been termed pathogen associated molecular patterns (PAMP). Lipopolysaccharides and teichoic acids shared by Gram-negative and Gram-positive bacteria respectively; mannans, conserved components of yeast cell walls; and the unmethylated Poly-cysteine guarine $(\mathrm{CpG})$ motif characteristic of bacterial, but not mammalian deoxyribonucleic acid (DNA), are characteristic PAMPs. While PAMPs are chemically quite distinct, they share certain features. PAMPs are: 1) produced only by microbes and not eukaryotic hosts; 2) essential for pathogenecity or survival of the microbe; 3 ) invariant structures shared by classes of pathogens [6-9].

The receptors of the innate immune system differ from antigen-specific receptors in several important ways. PRR's are expressed on many effector cells of 
the innate immune system. All professional antigenpresenting cells, macrophages, dendritic cells, bear PRR's. Second, expression of PRR's is not clonal; all such receptors displayed by cells of a given type have identical specificities. Third, following recognition of PAMP's, PRR's trigger effector cells to perform their effector functions immediately rather than after cellular proliferation [8].

PRR's belong to several families of proteins [10-35]. Functionally, PRR's can be divided into three classes: secreted, endocytic, and signalling receptors. The best characterized secreted PRR is the mannan-binding lectin, a member of the calcium-dependent lectin family that binds to microbial carbohydrates to initiate the lectin pathways of complement activation $[23,24]$.

Secreted PRR's function as opsonins by binding to microbial cell walls and identifying microbes for recognition by the complement system and phagocytes. The macrophage-mannose receptor, also a member of the calcium-dependent lectin family, is an endocytic PRR $[11,24]$. It specifically recognizes carbohydrates with large numbers of mannoses that are characteristic of micro-organisms and mediates their phagocytosis by macrophages. The macrophagescavenger receptor, another endocytic PRR, binds to bacterial cell walls and is an essential part of the clearance of bacteria from the circulation $[20,21,25$, 26]. Signaling PRR's recognize PAMP and activate signal transduction pathways that induce the expression of a variety of immune response genes including inflammatory cytokines and costimulatory molecules. Toll-like receptors (TLR) are signalling PRR's [27, 28]. Optimal signalling efficiency of TLR family members depends on association of secreted proteins MD-1 or MD-2 [29].

The mammalian toll family contains at least 10 family members. Different classes of pathogens are recognized by different, specialized members of the toll family. TLR4 appears to be responsible for the detection of Gram-negative bacteria. Recognition of lipopolysaccharide (LPS), a PAMP that represents a molecular signature of Gram-negative bacteria, mediates this detection process [30-32]. TLR2 is involved in recognition of Gram-positive bacteria through recognition of lipoteichoic acid and peptidoglycan [33]. TLR6 cooperates with TLR2 in detecting a subset of bacterial peptidoglycan [34]. TLR9 detects bacterial DNA sequences containing unmethylated cytosine-guanosine dinucleotides (CpGs) [35]. The specificity of the other six mammalian TLRs is the subject of intense investigation. Other members of the mammalian TLR family will most likely be specific for PAMP's characteristic of other classes of pathogens such as fungi (mannan, glucan and mycobacteria (lipoarabinomannan, muramyldipeptide)).

Activation of TLRs initiate signal transduction pathways that initiate and amplify inflammatory responses in the lung and modulate adaptive immune responses. The recognition and signalling pathways involved in the recognition of LPS have been most extensively studied. LPS initially interacts with a serum protein LPS binding protein, which transfers LPS to CD14, a receptor on macrophages and B-cells.
MD-2, a cell surface protein, is required for TLR4 mediated recognition of LPS. Accordingly, the LPS recognition complex most likely consists of three molecular components; CD14, TLR4, and MD-2 [14, $29,36]$. The binding of LPS to CD14 presumably leads to the association of CD14 with the TLR4-MD2 complex. Assembly of this complex may induce the dimerization of TLR4. TLR4 activation results in recruitment of the adapter protein MyD88, which is associated with the serine-threonine protein kinase interleukin-1 receptor-associated kinase (IRAK). This association leads to IRAK phosphorylation and association with the tumor necrosis factor-associated factor 6 (TRAF-6) adapter protein. Oligomerization of TRAF- 6 then activates a member of the mitogenassociated protein kinase, kinase, kinase (MAP3K) family which directly or indirectly leads to the activation of I $\mathrm{B}$ kinase 1 (IKK1) and I $\mathrm{B}$ kinase 2 (IKK2). These kinases target $\mathrm{I} \kappa \mathrm{B}$ for degradation and release nuclear factor $(\mathrm{NF})-\kappa \mathrm{B}$, which moves into the nucleus and induces transcriptional activation of a widevariety of inflammatory- and immune-response genes. Molecules induced by LPS-TLR4 interactions include: 1) signals that generate inflammatory responses including TNF- $\alpha$, interleukin (IL)-1, IL-6, interferon (IFN) $\alpha / \beta$ and chemokines; 2) signals that function as co-stimulators of T-cell activation, CD80 and CD86; and 3) signals that regulate the differentiation of lymphocytes including IL-4, IL-5, IL-10, IL-12, transforming growth factor (TGF)- $\beta$ and IFN- $\gamma$ [8].

\section{Inflammatory responses}

The generation of inflammation in the lower respiratory tract involves the co-ordinated expression of both pro- and anti-inflammatory cytokines (fig. 1). Following the recognition of microbial products,

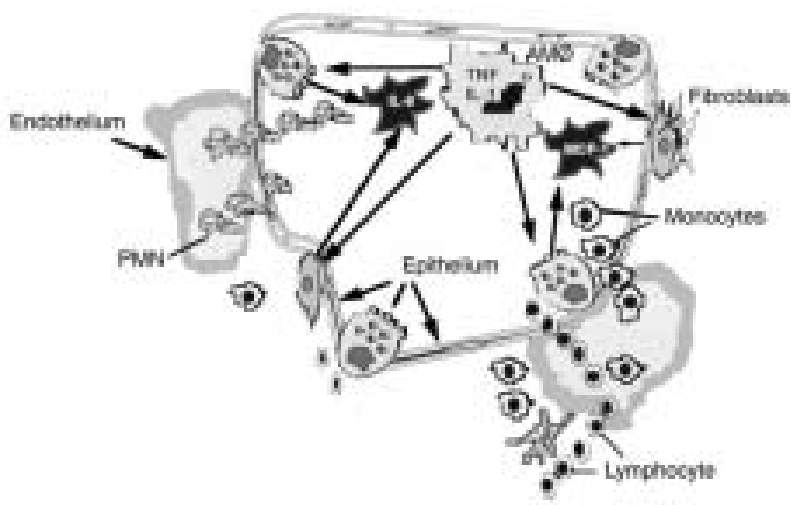

Fig. 1.-Development of an inflammatory response. Innate immune cells such as alveolar macrophages and monocytes recognize microbial products and secrete chemotaxins which recruit polymorphonuclear neutrophils ( $\left.\mathrm{PMN}^{\prime} \mathrm{s}\right)$ to the airspace. Innate immune cells also secrete early response molecules such as interleukin (IL)-1 and tumour necrosis factor (TNF), which activate alveolar epithelial cells and fibroblasts to produce chemokines. The development of an inflammatory response requires the induction of a coordinated network of cytokines, which involves cells throughout the alveolo-capillary wall. AM: alveolar macrophages; MCP: monocyte chemoattractant protein. 
TLR-mediated signalling results in the production of TNF- $\alpha$ and IL-1 $\beta$ [37-42]. Neutrophil recruitment is dependent on the orchestrated generation of these two early-response cytokines. TNF- $\alpha$ and IL-1 $\beta$ stimulate expression of adhesion molecules on vascular endothelial cells [43, 44]. P- and E-selectins expressed on endothelial cells interact with L-selectin on neutrophils leading to neutrophil rolling. Intercellular adhesion molecule (ICAM)-1 expression is also induced on the surface of the endothelium. Firm adhesion results following interactions between neutrophils and ICAM [43, 44].

CXC chemokines are also rapidly produced following microbial stimuli. IL-8, growth regulated oncogene (GRO) and epithelial-derived neutrophil attractant (ENA)-78 are produced by mononuclear phagocytes, neutrophils and endothelial cells in response to LPS, TNF- $\alpha$ and IL-1 $\beta$ [45-52]. IL-8, GRO and ENA-78 are all major polymorphonuclear neutrophil (PMN) chemoattractants. Expression of these CXC chemokines in the lung is stimulus specific. Thus, a network of cytokines rapidly induces PMN accumulation within the lung following recognition of microbial products [50].

Resident alveolar macrophages and recruited monocytes play a major role in amplifying the inflammatory response in the lower respiratory tract. Macrophages amplify the inflammatory response by stimulating cytokine production by cells that do not respond directly to bacterial products. Pulmonary fibroblasts, various pulmonary epithelial cells and pleural mesothelial cells all produce IL-8 in response to specific host-derived signals such as TNF- $\alpha$ or IL-1 $\beta$ [48-50]. All nucleated cells possess a functional receptor for IL-1 and TNF- $\alpha$ suggesting the importance of IL-1 and TNF- $\alpha$ as key cytokines in the augmentation of inflammatory responses. TNF- $\alpha$ and IL-1 induce all major cellular components of the alveolar-capillary membrane and/or airway of the lung to participate in the inflammatory response. Directed migration of leukocytes into the lung is dependent on the co-ordinated, sequential expression of chemokines.

\section{T-cell independent macrophage activation}

T-cell independent macrophage activation is one of the earliest events in the innate immune response. Cell-cell communication between macrophages and natural killer (NK) cells is required during this activation process [53]. Following microbial recognition and TLR-mediated signalling, macrophages release IL-12 and TNF- $\alpha$. These cytokines, in synergy, induce IFN- $\gamma$ production by NK cells. IFN- $\gamma$ is responsible for priming macrophages for microbicidal activity [54-57]. Both positive and negative feedback mechanisms regulate production of IL-12. IFN- $\gamma$, primarily an NK cell product, is the most potent upregulator of IL-12 production. IL-10, a product of macrophages and other cell types, is a potent inhibitor of IL-12 production [58]. IL-10 expression is delayed compared to that of IL-12 in vivo. This difference in kinetics is crucial to the role of IL-10 as a defence against excessive production of IL-12 and its pathological consequences.

Both LPS from Gram-negative bacteria and lipoteichoic acid from Gram-positive bacteria induce IL-12 via TLR-dependent mechanisms [59, 60]. IL12 production is also induced by bacterial DNA; $\mathrm{CpG}$ repeats are crucial for this induction [61, 62]. Dendritic cells can also be stimulated to produce IL-12 via TLR-mediated signalling pathways [63].

IL-12 is important to innate immune defence mechanisms in the setting of murine models of bacterial pneumonia [64]. Overexpression of IL-12 messenger ribonucleic acid (mRNA) and protein within the lung during bacterial pneumonia results in a $35 \%$ long-term survival in a model in which no animals that receive control adenovirus survive. In vivo inhibition of IL-12 bioactivity results in significant impairment in bacterial clearance and results in increased mortality. The mechanism by which compartmentalized overexpression of IL-12 improves survival is not completely understood. Treatment with anti-IFN- $\gamma$-antibodies or a soluble TNF receptor-Ig construct partially and completely attenuates survival benefits observed in animals receiving adenoviral vector-delivered IL-12. These studies indicate that IL-12 is an integral cytokine in innate immune responses against Gram-negative bacterial pathogens.

The delayed expression of IL-10 compared to that of IL-12 in vivo make it a likely, effective downregulator of the IL-12 response [65]. Blockade of IL-10 adversely affects the outcome of intravenous LPS challenges in mice [66]. IL-10 -/- mice infected with Toxoplasma overproduce IL-12, which results in a lethal syndrome [67]. In aggregate, these studies suggest that IL-10 is a critical defence against excessive production of IL-12 and its pathological consequences.

\section{Dendritic cell maturation and differentiation}

Antigen presenting cells (APC) provide an essential link between innate and adaptive immunity. Dendritic cells (DC) are the most capable initiators of adaptive immune responses [68, 69]. DC are localized at epithelial borders throughout the mammalian host where they recognize pathogens and/or micro-environmental tissue damage and signal the presence of "danger" to cells of adaptive immunity [7, 70, 71]. DC capture antigen, migrate to draining lymphoid organs and, after a process of maturation, select antigen-specific lymphocytes to which they present processed antigen, thereby initiating adaptive immune responses [68, 69].

DC are believed to be a complex system of cells encompassing multiple subsets with potentially distinct biological functions [69, 72-81]. DC comprise three distinct populations, including two within the myeloid lineage, Langerhans cells and interstitial DC and one within the lymphoid lineage. Within these pathways, DC at different maturational stages may differ in phenotype, function and localization. Three stages of maturation have been delineated including precursor DC found in blood and lymphatics, 
tissue-residing immature DC, and mature DC present within secondary lymphoid organs [72, 82-89].

\section{Dendritic cell development from blood precursors}

The study of DC biology has been impeded by the rarity of DC in vivo and difficulties in purifying DC. Considerable progress has been made in understanding DC maturation by studying human DC in vitro.

DC progenitors represent a small fraction of CD34+ haematopoietic progenitor cells in bone marrow or peripheral blood. Granulocyte macrophage colony stimulating factor (GM-CSF) and $\mathrm{TNF}-\alpha$ stimulate growth and differentiation of DC progenitors into DC precursors. This process can be enhanced and/or modulated by multiple cytokines including c-KIT ligand, Flt-3-ligand, IL-3, TGF $\beta$, IL-4 and IL-13. TNF- $\alpha$, however, appears to be a critical factor in DC development [73, 90]. Myeloid DC are closely related to monocytes. Monocytes generate myeloid DC when cultured with GM-CSF and IL-4 (IL-13). Conversely, immature myeloid DC differentiate to macrophage phenotypes when cultured with GM-CSF [91-95]. The choice of whether a monocyte becomes a DC or a macrophage may in part be influenced in vivo by the endothelium. Monocytes that transmigrate the endothelium in the ablumenalto-lumenal direction (during entry into lymphatics) become $\mathrm{DC}^{\prime}$ s; those that remain in the tissues become macrophages [96].

\section{Dendritic cell migration and maturation}

Chemokines and their receptors play a major role in directing the right cells to the right places (fig. 2). Immature DC's as well as monocytes, which represent immediate DC precursors, express various receptors for inflammatory chemokines such as CCR1 (receptor for regulated on activation, normal $\mathrm{T}$-cell expressed and secreted (RANTES), CCR2 (receptor shared by monocyte chemoattractant protein (MCP)-1-MCP4), CCR3 (receptor for eotaxin), CCR5 (receptor for monocyte inflammatory protein (MIP)- $1 \alpha$ and $-\beta$ and RANTES), and CCR6 (receptor for MIP-3 $\alpha$ ) [97-101]. As a result of these receptor-ligand interactions, monocytes and immature DC are rapidly recruited to organs undergoing inflammatory responses. LPS or TNF- $\alpha$ stimulate DC to produce large

a)

b)
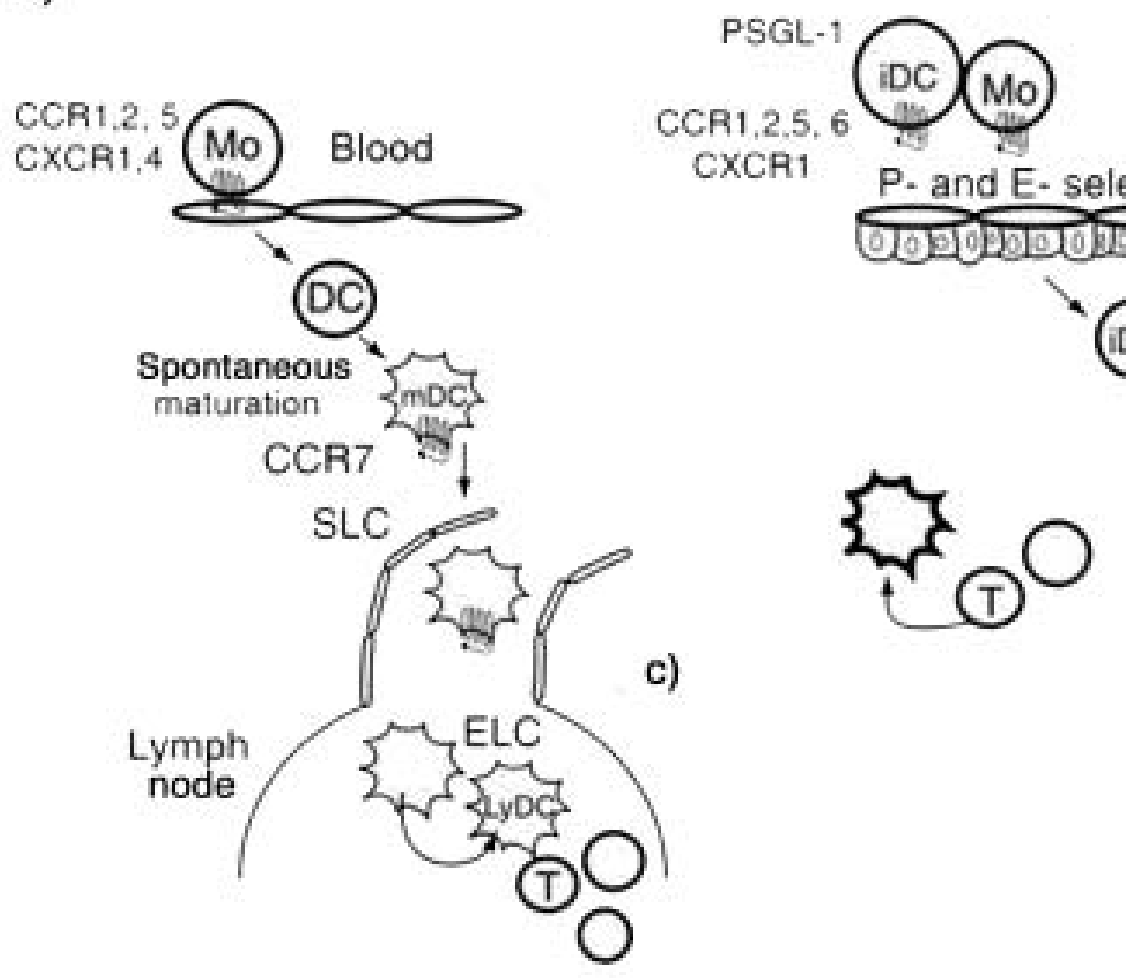

c)

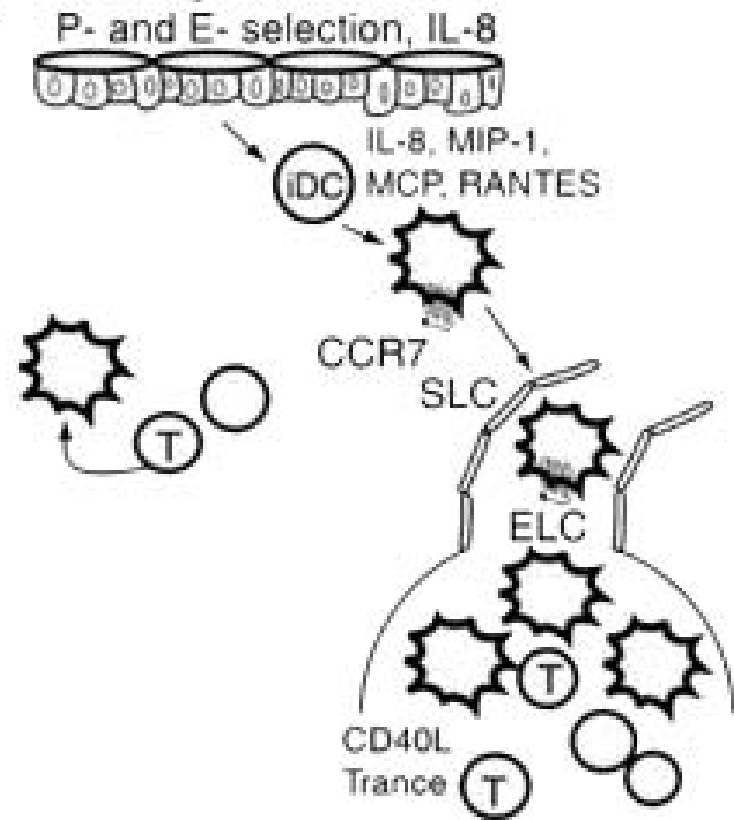

Fig. 2.-Migration and activation of dendritic cells (DC) controls the induction of immune responses and chronic inflammation. a) tolerance, b) priming, c) chronic inflammation. Immature DC are attracted by inflammatory chemokines into sites of inflammation. Microbial products induce DC maturation and activation. Chemokines induce DC migration to draining lymph nodes. In the lymph nodes, activated T-cells further enhance DC activation and survival via CD40L and TRANCE. The presence of many highly-activated DC induce a productive T-cell response within the node. Mature DC that fail to migrate to lymph nodes and remain in peripheral organs may serve as initiation sites for chronic inflammatory responses. Mature DC produce chemokines in peripheral organs to attract maturing DC as well as recently activated T-cells. In aggregate, these cells maintain a chronic inflammatory reaction. RANTES: regulated on activation, normal T-cell expressed and secreted; TRANCE: tumour necrosis factor-related activation-induced cytokine; CCR: chemokine receptor; MO: monocyte; MDC: macrophage-derived chemokine; SLC: secondary lymphoid chemokine; ELC: EBII-ligand chemokine; MIP-1: macrophage inflammatory protein; MCP: monocyte chemoattractant protein. 


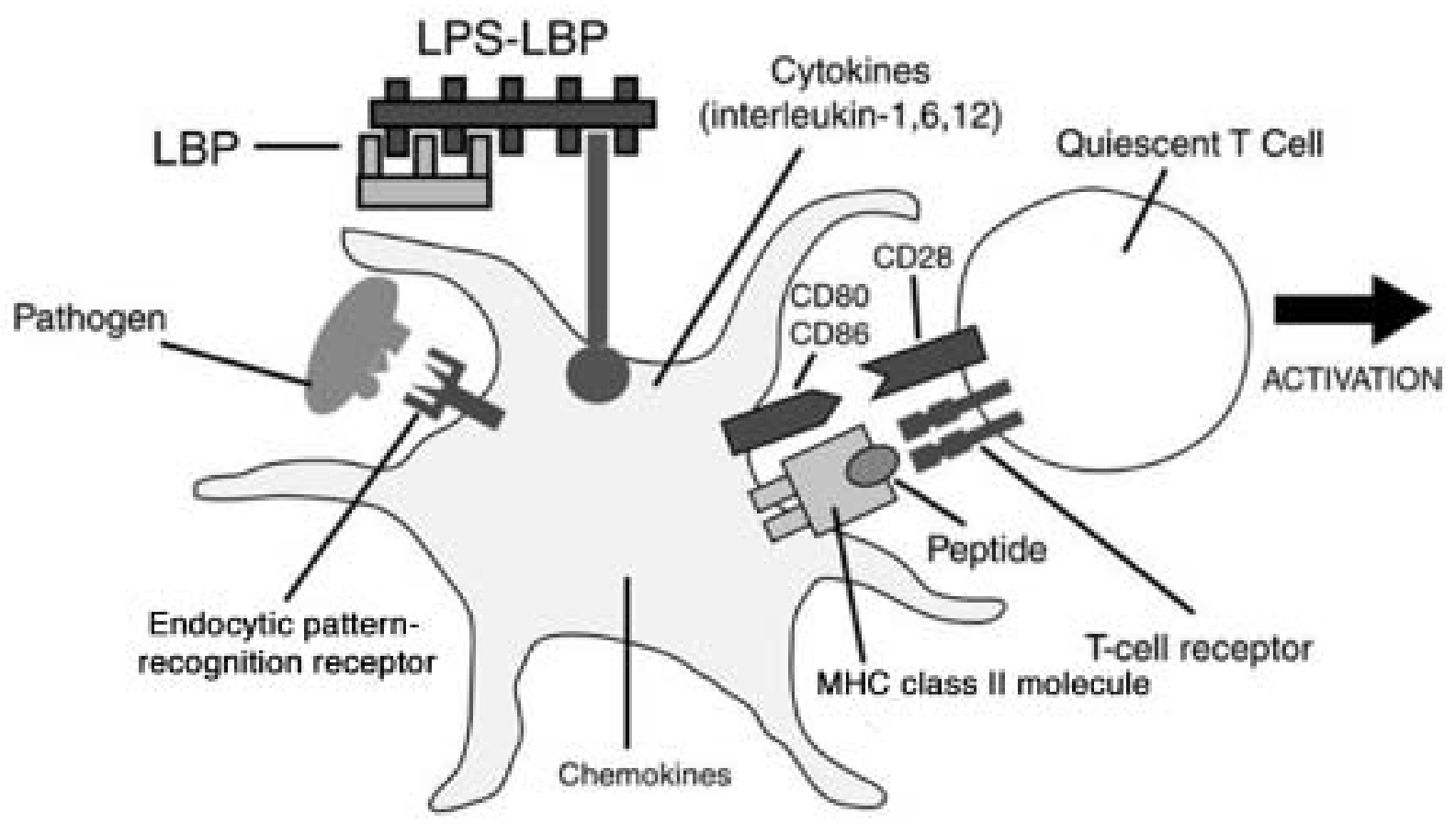

Fig. 3.-Receptors and cytokines involved in innate immune control of adaptive immune responses. Endocytic pattern recognition receptors such as the mannose receptor, bind to components of microbes and mediate the phagocytosis of pathogens by antigen presenting cells (APC). Ingested micro-organisms are processed to general antigenic peptides, which complex with major histocompatibility complex (MHC) class II molecules on the surface of APC. MHC-microbial peptide complexes are recognized by T-cell receptors. Pathogen associated molecular patterns (PAMP's) recognized by Toll-like receptors activate APC to express cytokines, chemokines and co-stimulatory molecules. Pathogen recognition receptors (PRR's) play crucial roles in the generation of both peptide-MHC molecule complexes and the expression of co-stimulatory molecules required for activation of T-cells. LPS: lipopolysaccharide; LBP: lipopolysaccharide binding protein.

amounts of inflammatory chemokines, which contribute to the further recruitment of immature DC's. After arrival at sites of inflammation, DC capture antigens and are stimulated to mature by inflammatory cytokines such as TNF- $\alpha$ or IL-1 or by bacterial or viral products such as LPS, $\mathrm{CpG}$ or doublestranded ribonucleic acid (RNA) [102].

The maturation process leads to an upregulation of co-stimulatory molecules (fig. 3). T-cells require at least two signals to become activated; one is a complex of a peptide and a major histocompatibility complex (MHC) molecule, and the other is a co-stimulatory signal mediated by molecules such as CD80 and CD86 on the surface of APC. It is only when the APC expresses both antigen and CD80 or CD86 molecules that T-cells can be activated. Recognition of an antigen in the absence of DC80 or CD86 molecules leads to permanent inactivation or apoptosis of T-cells [103, 104].

The expression of CD80 and CD86 molecules on the surface of APC is controlled by innate immune system signals [27]. TLR's induce these molecules to appear on APC when they recognized their cognate PAMP's. Since PAMP's occur only on pathogens, TLR's induce CD80 and CD86 molecules only in the presence of infection. Accordingly, a T-cell receives both of the signals required for activation only if its receptor binds to the peptide that was derived from the pathogen that induced the expression of CD80 or
CD86 molecules through its PAMP (i.e. LPS). This mechanism insures that, normally, only pathogenspecific T-cells are activated. Innate immune recognition, thus, controls all major aspects of the adaptive immune response through the recognition of infectious microbes and the induction of signals required for the triggering of specific immunity.

The maturation process also leads to migration to secondary lymphoid organs. As a consequence of chemokine production, maturing $\mathrm{DC}^{\prime}$ s down-regulate CCR1, CCR5 and CCR6 [100, 101]. Conversely, receptors for constitutive chemokines CCR4, CCR7 and CXCR4 are upregulated in maturing DC. CCR7 is most likely of particular importance to the movement of mature DC into lymphatics since the ligand secondary lymphoid tissue chemokine (SLC) is produced by lymphatic endothelial cells [105]. From the lymphatics, DC's drain to the lymph nodes where final positioning within the $\mathrm{T}$-cell area may be controlled by other CCR7 ligands including ELC, produced by resident mature DC and MIP-3 $\beta$ [106].

DC are important sentinels of the immune system in the lung [107] (fig. 4). Airway and alveolar epithelial cells most likely participate in the differentiation of DC in the lung by secreting cytokines as a direct response to pathogens and secondly, by acting as paracrine cells, which amplify ongoing airway and parenchymal inflammation through the production of cytokines in response to inflammatory mediators. 


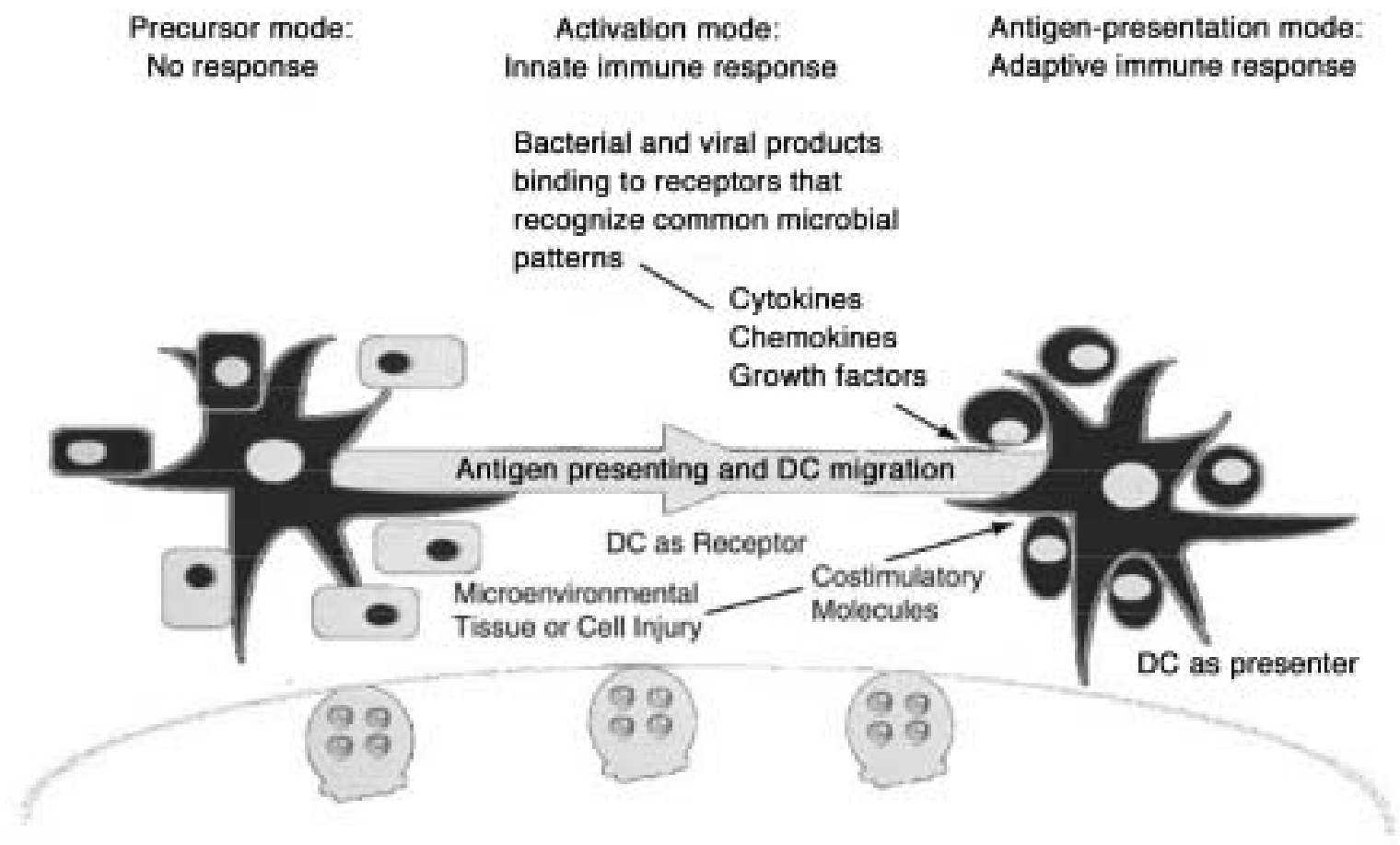

Fig. 4. - The immunological role of lung dendritic cells (LDC). Pulmonary parenchymal and mesenchymal cells present in the airway and lower respiratory tract participate in the differentiation of dendritic cells by releasing cytokines, chemokines and growth factors following exposure to microbial products or as a result of micro-environmental cell injury. These cytokines, chemokines and growth factors lead to: 1) migration of DC from blood to lung; 2) maturation/activation of DC within the lung; and 3) migration of DC to the node. Dendritic cells are sentinels of the immune system in the lung.

Micro-environmental airway or alveolar tissue injury might also initiate the activation of pulmonary DC. The precise signals that injured cells might deliver are uncertain but could include cytokines, oxygen radicals or altered glycosylated cell-surface molecules. Pulmonary epithelial cells and DC most likely participate in a differentiation network within the innate immune system [107-109].

\section{T-cell differentiation}

Naïve T-lymphocytes differentiate into distinct effector cells depending on the cytokine milieu they encounter during activation (fig. 5). Two subsets of CD4 and CD8 T lymphocytes have been defined on the basis of their lymphokine secretion patterns. T1 cells generate IL-2, IFN- $\gamma$, TNF- $\alpha$ and GM-CSF; T1 cells mediate delayed-type hypersensitivity responses. T2 cells produce IL-4, IL-5 and IL-10; T2 cells are responsible for B-lymphocyte maturation and immunoglobulins isotype switching $[110,111]$.

IL-12 is the single most important factor required for the efficient differentiation of T1 cells [112-114]. IL-12 is induced by bacteria, fungi, viruses or their products by a T-independent pathway and by a T-celldependent pathway mediated through CD40-CD40 ligand (CD40L) interactions [59, 63, 115, 116]. IL-12 and IFN- $\gamma$ induced by IL-12, create a microenvironment during the early inflammatory phase of an infection in which antigen-specific CD4 and CD8 $\mathrm{T}$-cells are preferentially induced to differentiate into
T1 cells that produce even higher levels of IFN- $\gamma$ [117-119].

IL-12 is a $75 \mathrm{kDa}$ heterodimer produced by macrophages and DC [120, 121]. IL-12 directs T1 development from antigen-stimulated naïve $\mathrm{T}$-cells and activates signal transducers and activators of transcription (STAT) 3 and STAT4 in T1 cells. Gene deletion of IL-12 or STAT4 markedly reduces T1 responses demonstrating that IL-12 signalling through this pathway is required in vivo [122-125]. Functional receptors for IL-12 appear to be restricted to recently activated, uncommitted cells and to $\mathrm{T} 1$ cells. These receptors are lost during the development of T2 cells $[124,126]$. T1 development is also dependent on IFN- $\gamma$. The effects of IFN- $\gamma$ may be mediated via its action on the macrophage to upregulate IL-12 production or by direct effects on the T-cell. The molecular basis of IL-12 responsiveness is in part dependent upon the expression of IL-12R. IL-4 downregulates expression of IL-12R $\beta 2$; IFN- $\gamma$ upregulates expression of IL-12R $\beta 2$ [124, 126, 127]. IL-18 is also importantly involved in T1 development. This cytokine promotes proliferation in IFN- $\gamma$ production by T1 clones and lines and NK cells. IL-18 belongs to the IL-1 family. IL-18 does not drive T1 development, but potentiates IL-12-induced T1 development. IL-18 does not activate STAT4 in Th1 cells. IL-18 signals through the IRAK pathway [128].

Induction of TNF- $\alpha$ appears to be a critical early step in the afferent phase of $\mathrm{T} 1$ cell-mediated immunity against certain microbes. A single dose of anti-TNF- $\alpha$ antibodies at the onset of a moderately 


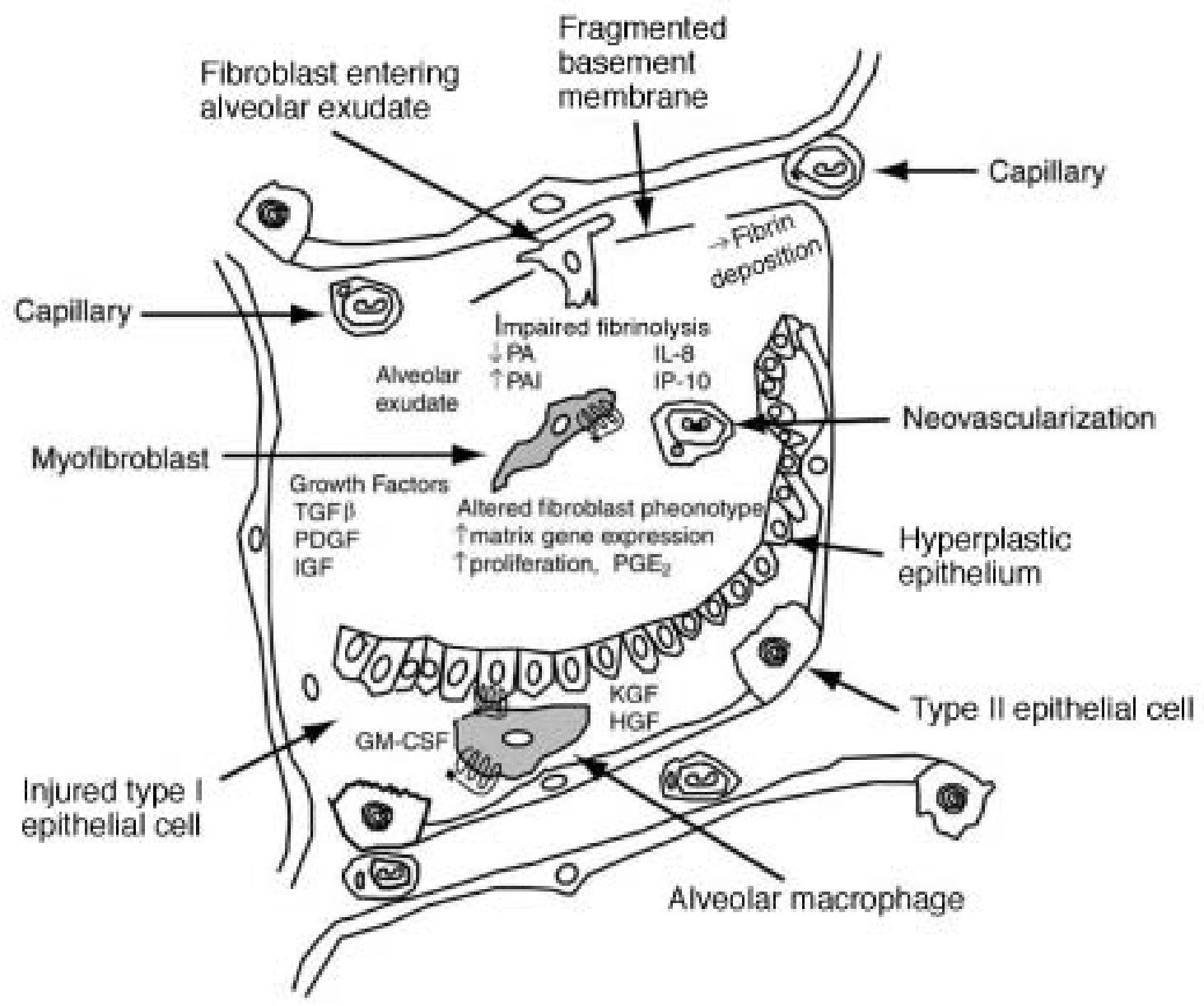

Fig. 5. - Regulation of T-lymphocyte responses. Cells of the innate immune system recognize pathogen associated molecular patterns (PAMP's) and secrete cytokines, which regulate T-subset differentiation. The cytokine milieu in which naive T-cell differentiation occurs determines the eventual cytokine profile and effector function of T-lymphocytes. The innate immune system and its cytokines are crucial determinants of the type of effector cells generated during adaptive immune responses following antigen challenge. IL: interleukin; GM-CSF: granulocyte macrophage colony stimulating factor; PA: plasminogen activator; PAI: plasminogen activator inhibitor; TGF: transforming growth factor; PDGF: platelet derived growth factor; IGF: insulin-like growth factor; KGF: keratinocyte growth factor; HGF: hepatocyte growth factor; $\mathrm{PGE}_{2}$ : prostaglandin E-2.

virulent Cryptococcus neoformans infection results in a four-log increase in lung colony forming units (CFU's) and a five-log increase in brain CFU 5 weeks later. Delaying the induction of TNF- $\alpha$ alters the usual, protective $\mathrm{T} 1$ response induced by C. neoformans to a nonprotective $\mathrm{T} 1$ response. These data suggests that TNF- $\alpha$ induced activation of macrophages or DC is required for effective production of IL-12 by these cells [129, 130].

Chemokine signalling also plays a role in T1/T2 immune response polarization within the lung. In mice lacking CCR2, the primary receptor for MCP-1, intratracheal inoculation with $C$. neoformans results in delayed macrophage and CD8 T-cell recruitment as well as a lack of cryptococcal clearance. CCR2deficient mice exhibit significant dissemination of
C. neoformans to the spleen and brain at 6 weeks postinfection. In contrast to the T1-type response generated by CCR2 expressing mice, CCR2-deficient mice produce a strong $\mathrm{T} 2$ response to pulmonary $C$. neoformans infection. CCR2 -/- mice generate an immune response characterized by chronic pulmonary eosinophilia, crystal deposition in the lungs, pulmonary leukocyte production of IL-4 and IL-5, but not IFN- $\gamma$ and increased serum IgE. In aggregate, these results demonstrate that expression of CCR2 is required for the development of a T1-type response to $C$. neoformans infection. Lack of CCR2 results in a switch to a T2-type response [131].

CCR2 deficient mice evidenced defective macrophage and $\mathrm{CD} 8+\mathrm{T}$-cell recruitment to the lung. CD8 depletion during C. neoformans infections results 
in the production of predominantly $\mathrm{T} 2$ cytokines by CD4+ T-cells [132]. Thus, IFN- $\gamma$ production by CD8+ T-cells might be important for the development of T1-type CD4 T-cell immunity to C. neoformans. Alternatively, CD8 T-cell produced IFN- $\gamma$ may be required to prime macrophages or DC for IL-12 production. Lack of recruitment of appropriate DC to the lung might also explain the CCR2-induced effect.

The development of T2 responses requires IL-4 during priming of naïve $T$ cells. Cellular sources of this cytokine other than T2 cells are uncertain. Basophils, mast cells, $\gamma \delta$ T-cells and an NK1.1+, CD4+, CD8T-lymphocyte have all been reported to produce IL-4 [133].

Distinct murine DC subsets and their growth factors can direct specific T-cell subset development. $\mathrm{CD} 8 \alpha+\mathrm{DC}$ elicit T1 responses while CD $8 \alpha-\mathrm{DC}$ favour T2 responses [85, 134]. Repeated injections of either CD8 $\alpha+$ or CD8 $\alpha$-DC yield strongly polarized $\mathrm{T} 1$ and $\mathrm{T} 2$ responses respectively. CD $8 \alpha+\mathrm{DC}$ can be induced to secrete IL-12, which appears essential for their T1 induction [72, 135, 136]. The DC molecules that induce $\mathrm{T} 2$ responses are unknown, although IL-10 is a candidate molecule. CD8 $\alpha+$ DC are induced to secrete IFN- $\gamma$ by IL-12 [137]. Both DC subsets can efficiently prime antigen specific CD8+ T-cells and induce cytotoxic T-lymphocyte activity in vivo [138]. It is unknown whether such DC induce distinct cytokine profiles in CD8 T-cells.

Differential expression of co-stimulatory molecules may also be crucial to this polarization process [139, 140]. CD86 is constitutively expressed on DC and macrophages whereas CD80 is not. The outcome of CD80 and CD86 co-stimulation is different. CD86 co-stimulates the production of IL-4 as well as IL-2 and IFN- $\gamma$. Thus, after CD86 co-stimulation, an initial source of IL-4 is available. CD86 co-stimulation provides only a moderate signal for $\mathrm{T} 2$ cell differentiation; additional signals are almost surely required to achieve high levels of IL-4 production.

Multiple pathways have evolved to manipulate the immune response to microbes. Functionally distinct DC subsets exist, but plasticity in DC function exists within these subsets. A system in which DC function was not plastic would not allow the flexibility to evolve differential $\mathrm{T}$-cell responses during the course of an infectious process. The optimal situation for T-lymphocyte differentiation would be a circumstance where functionally different DC subsets are geographically segregated and poised to mount a given T-cell subset response rapidly in response to a given product. However, as the response evolves, the function of these DC may be modified directly, by the pathogen itself, or by cytokines released by neighbouring bone marrow-derived cells, mesenchymal cells or parenchymal cells. The final T-cell response is accordingly determined by: 1) the microbial product, 2) the receptor on the DC through the which the microbial product signals, 3) the DC subset itself and 4) the local cytokine micro-environment produced by neighbouring bone marrow-derived cells, mesenchymal cells and parenchymal cells.

\section{T-cell dependent macrophage recruitment and activation}

The protective delayed type hypersensitivity response relies on the prompt recruitment of mononuclear cells from the blood in response to chemotaxins produced by both specific T-lymphocytes and nonspecifically activated cells [141, 142]. Mononuclear cell recruitment prevents systemic dissemination of the microbe from the lungs and is also required for effective intrapulmonary microbicidal activity. Chemokines play a crucial role in the recruitment of mononuclear cells during the specific immune response to $C$. neoformans $[143,144]$. Intrapulmonary levels of MCP-1 and MIP-1 $\alpha$ increase following intratracheal inoculation of $C$. neoformans. MCP-1 levels are increased during the first 1-2 weeks of infection, whereas MIP- $1 \alpha$ increases 2-3 weeks after infection. MCP-1 and MIP-1 $\alpha$ are both crucial to the efferent phase of the immune response since administration of neutralizing antibodies to either MCP-1 or MIP- $1 \alpha$ results in a three-fold increase in fungal burden at 2 weeks postinfection. Neutralization of MCP-1 abolishes the recruitment of macrophages and reduces CD4+ T-cell recruitment. Similarly, MIP- $1 \alpha$ neutralization reduces macrophage and neutrophil recruitment significantly. Induction of MIP- $1 \alpha$ production is largely dependent on MCP-1 production given that MCP-1 levels were not affected by neutralization of MIP- $1 \alpha$ but neutralization of MCP-1 significantly decreased MIP- $1 \alpha$ within the lungs of infected mice. Thus, MCP-1 and MIP-1 $\alpha$ comprise a chemokine network crucial to the maximal recruitment of mononuclear phagocytes during the effector phase of a cell-mediated immune response.

\section{Tissue remodelling and repair}

The pulmonary parenchyma and airways must be remodelled and repaired following microbial infection and following injury. Repair and fibrotic processes are crucially dependent on growth factors for fibroblasts and epithelial cells including plateletderived growth factor (PDGF), transforming growth factor alpha and beta (TGF- $\alpha$, TGF- $\beta$ ), insulin-like growth factor and GM-CSF [145-151] (fig. 6). PDGF induces fibroblast proliferation and collagen production. The wound-healing effects of PDGF are macrophage-dependent in most models. TGF- $\alpha$ stimulates the closure of wounds induced in cultures of type II alveolar epithelial cell in vitro. TGF- $\alpha$ most likely plays a role in epithelial cell repair in the lungs following injury [148, 149]. TGF- $\beta$ has important effects on the turnover of matrix proteins and the proliferation of fibroblasts. TGF- $\beta$ activates genes that favor the production on matrix proteins and down-regulates the production of matrix metalloproteinases that digest matrix in the interstitium and alveolar spaces. In aggregate, the effects of TGF- $\beta$ shift the balance in favour of matrix accumulation [151]. GM-CSF has a protective effect on repair processes following bleomycin-induced injury [152, 153]. The protective effect is mediated in part by 




Fig. 6. - Fibroproliferative changes in fibrotic lung diseases. Altered growth factor production during fibroproliferative responses leads to an altered fibroblast phenotype which favours matrix deposition. Epithelial cell growth factors are importantly involved in regulating epithelial cell repair. Growth factors play crucial roles in regulating rates of apoptosis. Chemokines play crucial roles in regulating neovascularization during the repair process. IL: interleukin; LPS: lipopolysaccharide; IFN: interferon; GM-CSF: granulocyte macrophage colony stimulating factor; Th: T-helper cell; NK: natural killer; MIP: macrophage inflammatory protein; MCP: monocyte chemoattractant protein.

GM-CSF-induced production of prostaglandin $(\mathrm{PGE})_{2}$ by pulmonary macrophages. $\mathrm{PGE}_{2}$ has crucial down-regulatory effects on fibroblasts including decreased fibroblast proliferation and decreased matrix production by fibroblasts. Regulation of chemokine receptor expression is also crucial to appropriate pulmonary repair. Fluorescein-isothiocyanate (FITC)-induced pulmonary fibrosis is regulated by MCP-1 and CCR2 expression [154]. FITC challenge results in the generation of MCP-1. MCP-1 signalling via the CCR2 receptor results in the generation of pro-fibrotic signals. Mice deficient for CCR2 are protected from the fibrotic response. The protection from fibrosis was relatively specific to the deletion of the CCR2 gene as mice with the deletion in the CCR5 gene were not protected from FITC-induced pulmonary fibrosis. Thus, a crucial role for CCR2 and its ligand(s) exists during the generation of a fibrotic response to lung injury.

Chemokines and their receptors also play a central role in regulating angiogenesis, a central biological event in repair and remodelling. IL-8 and ENA-78 are $\mathrm{CXC}$ chemokines that contain the sequence GLULEU-ARG (ELR motif). ELR motif-containing CXC chemokines are potent angiogenic factors. In contrast, platelet factor-4 and IFN- $\gamma$ inducible protein-10 are CXC chemokines that lack the ELR motif. Non-ELR containing chemokines can inhibit angiogenic activity of both ELR-CXC chemokines and structurally unrelated macrophage-derived angiogenic factor-bFGF [155].

\section{Attributes of the pulmonary-cytokine receptor interaction}

The molecular dialogue between cytokines and their receptors has the attributes of language, namely abstraction, combinatorial signals, semantics, syntax and context [156]. Cytokines serve as abstractions of another reality. Cytokines report the presence of microbes and injured epithelia. Combinatorial signals make it possible to use a limited number of elements to transmit a large number of signals. Cytokines can 
be combined in many different patterns to create numerous, very complex messages. Semantics is the study of relationships between a sign and its meaning. The meaning of the sign can be defined operationally by the response that the sign induces. Cytokines in this context clearly have meaning since they induce measurable effects. Syntax refers to the organized structure of a string of signals; the grammar of the message. Cytokine signals, accordingly, have a syntax; the order in which cytokine signals are delivered is clearly important to the message. Finally, cytokines create a context. The milieu that surrounds a signal can clearly determine the nature of the response that it elicits. The meaning of an antigen, the nature of the response it elicits, depends greatly on the cytokine context in which the antigen appears. A T1 mix of cytokines predicates a very different response to a given antigen than does a T2 mix of cytokines.

Cytokines and their receptors comprise a "language" that is crucial to cellular function. Cell-cell communications proceed as an ongoing chemical dialogue that functionally connects recognition with responses. Understanding this language should permit the use of its component parts as tools to manipulate cellular behaviour in various clinical settings.

\section{References}

1. Boehm U, Klamp T, Groot M, et al. Cellular responses to interferon gamma. Ann Rev Immunol 1997; 15: 749-795.

2. Mantovani A. The chemokine system: redundancy for robust outputs. Immunol Today 1999; 20: 254-257.

3. Toews GB. Pulmonary clearance of infectious agents. In: Fishman AP, ed. Pulmonary Diseases and Disorders. Philadelphia, 1997; pp. 1891-1904.

4. Hughes AL, Yeager M. Molecular evolution of the vertebrate immune system. BioEssasy 1997; 19: 777 786.

5. Janeway CA Jr. Approaching the asymptote? Evolution and revolution in immunology. Cold Spring Harbor Symp Quant Biol 1989; 54: 1-13.

6. Janeway CA Jr. The immune system evolved to discriminate infectious nonself from noninfectious self. Immunol Today 1992; 13: 11-16.

7. Fearon DL, Locksley RM. The instructive role of the innate immunity in the acquired immune response. Science 1996; 272: 50-54.

8. Medzhitov R, Janeway C Jr. Innate immunity. $N$ Eng J Med 2000; 343: 388-344.

9. Medzhitov R, Janeway C Jr. Innate immunity: impact on the adaptive immune response. Curr Opin Immunol 1997; 9: 4-9.

10. Suzuki N, Yamamoto K, Toyoshima S, Osawa $\mathrm{T}$, Irimura T. Molecular cloning and expression of cDNA encoding human macrophage C-type Lectin. Its unique carbohydrate binding specificity for $\mathrm{Tn}$ antigen. J Immunol 1996; 156: 128-135.

11. Stahl PD. The mannose receptor and other macrophage lectins. Curr Opin Immunol 1992; 4: 49-52.

12. Jiang W, Swiggard WJ, Heufler C, et al. The receptor DEC-205 expressed by dendric cells and thymic epithelial cells is involved in antigen processing. Nature 1995; 375: 151-153.
13. Ulevitch RJ, Tobias PS. Receptor-dependent mechanisms of cell stimulation by bacterial endotoxin. Аnnu Rev Immunol 1995; 13: 437-457.

14. Wright SD, Ramos RA, Tobias PS, et al. CD 14, a receptor for complexes of lipopolysaccharride (LPS) and LPS binding protein. Science 1990; 249: 14311433.

15. Pugin J, Heumann D, Tomasz A, et al. CD14 is a pattern recognition receptor. Immunity 1994; 1: 509516.

16. Wright SD. CD14 and innate recognition of bacteria. J Immunol 1995; 155: 6-8.

17. Hampton RY, Golenbock DT, Penman M, et al. Recognition and plasma clearance of endotoxin by scavenger receptors. Nature 1991; 352: 342-344.

18. Elomaa O, Kangas M, Sahlberg C, et al. Cloning of a novel bacteria-binding receptor structurally related to scavenger receptors and expressed in a subset of macrophages. Cell 1995; 80: 603-609.

19. Krieger M, Herz J. Structures and functions of multiligand lipoprotein receptors: macrophage scavenger receptors and LDL receptor-related protein (LRP). Annu Rev Biochem 1994; 63: 601-637.

20. Kodama T, Freeman M, Rohrer L, et al. Type I macrophage scavenger receptor contains alpha-helical and collagen-like coiled coils. Nature 1990; 343: 531535.

21. Rohrer L, Freeman M, Kodama T, et al. Coiled-coil fibrous domains mediate ligand binding by macrophage scavenger receptor type II. Nature 1990; 343: 570-572.

22. Elomaa O, Kangas M, Sahlberg C, et al. Cloning of a novel bacteria-binding receptor structurally related to scavenger receptors and expressed in a subset of macrophages. Cell 1995; 80: 603-609.

23. Epstein J, Eichbaum Q, Sheriff S, et al. The collectins in innate immunity. Curr Opin Immunol 1996; 8: 29-35.

24. Fraser IP, Koziel H, Ezekowitz RA. The serum mannose-binding protein and the macrophage mannose receptor are pattern recognition molecules that link innate and adaptive immunity. Semin Immunol 1998; 10: 363-372.

25. Suzuki H, Kurihara Y, Takeya M, et al. A role for macrophage scavenger receptors in atherosclerosis and susceptibility to infection. Nature 1997; 386: 292-296.

26. Thomas CA, Li Y, Kodama T, et al. Protection from lethal gram-positive infection by macrophage scavenger receptor-dependent phagocytosis. J Exp Med 2000; 191: 147-156.

27. Medzhitov R, Preston-Hurlburt P, Janeway CA Jr. A human homologue of the Drosophila Toll protein signals activation of adaptive immunity. Nature 1997; 388: 394-397.

28. Rock FL, Hardiman G, Timans JC, et al. A family of human receptors structurally related to Drosophila Toll. Proc Natl Acad Sci USA 1998; 95: 588-593.

29. Shimazu P, Akashi S, Ogata H, et al. MD-2, a molecule that confers lipopolysaccharide responsiveness on Toll-like receptor 4. J Exp Med 1999; 189: 1777-1782.

30. Poltorak A, He X, Smirnova I, et al. Defective LPS signaling in $\mathrm{C} 3 \mathrm{H} / \mathrm{HeJ}$ and $\mathrm{C} 57 \mathrm{BL} / 10 \mathrm{ScCr}$ Mice: mutations in Tlr4 gene. Science 1998; 282: 2085-2088.

31. Quershi ST, Lariviere L, Leveque G, et al. Endotoxintolerant mice have mutations in Toll-1ike receptor 4. 
J Exp Med 1999; 189: 615-625. [Erratum, J Exp Med 1999; 189: 1518a.].

32. Hoshino K, Takeuchi O, Kawai T, et al. Cutting edge: Toll-1ikc receptor 4 (TLR-4)-deficient mice are hyporespnsive to lipopolysaccharidc: evidence for TLR4 as the Lps gene product. J Immunol 1999; 162: 37493752 .

33. Takeuchi O, Hoshino K, Kawai T, et al. Differential roles of TLR2 and TLR4 in recognition of gramnegative and gram-positive bacterial cell wall components. Immunity 1999; 11: 443-451.

34. Ozinsky A, Underhill DM, Fontenot JD, et al. The repertoire for pattern recognition of pathogens by the innate immune system is defined by cooperation between toll-like receptors. Proc Natl Acad Sci USA 2000; 97: 13766-13771.

35. Hemmi $\mathrm{H}$, Takeuchi $\mathrm{O}$, Kawai $\mathrm{T}$, et al. A toll-like receptor recognizes bacterial DNA. Nature 2000; 408: 740-745.

36. Wright SD, Tobias PS, Ulevitch RJ, et al. Lipopolysaccharide (LPS) binding protein opsonizes LPSbearing particles for recognition by novel receptor on macrophages. J Exp Med 1989; 170: 1231-1241.

37. Beutler B. The tumor necrosis factors: cachectin and lymphotoxin. Hosp Pract 1990; 2: 45-46.

38. Sherry B, Cerami A. Cachectin/tumor necrosis factor exert endocrine, paracrine and autocrine control of the inflammatory response. J Cell Biol 1988; 107: $1269-1277$.

39. Larrick JW, Kunkel SL. The role of tumor necrosis factor and interleukin-1 in the immunoinflammatory response. Pharm Res 1988; 5: 129-139.

40. Le J, Vilcek J. TNF and IL-1: cytokines with multiple overlapping biological activities. Lab Invest 1987; 56: 234-282

41. Strieter RM, Kunkel SL, Bone RL. Role of tumor necrosis factor in disease states and inflammation. Crit Care Med 1993; 21: 5447-5463.

42. Kunkel SL, Chensue SW, Lukacs NW, et al. Macrophage-derived cytokines in lung inflammation. In: Lung Macrophages and Dendritic Cells in Health. New York, Marcel Dekker, 1997; pp. 183-202.

43. Albelda SM, Smith CW, Ward PA. Adhesion molecules and inflammatory injury. FASEB J 1994; 8: 504-512.

44. Springer TA. Traffic signals for lymphocyte recirculation and leukocyte immigration: the multistep paradigm. Cell 1994; 76: 301-314.

45. Strieter RM, Chensue SW, Basha MA, et al. Human alveolar macrophage gene expression of interleukin-8 by TNF- $\alpha$, LPS and IL- $\beta$. Am J Respir Cell Mol Biol 1990; 2: 321-326.

46. Goodman RB, Strieter RM, Frevert CW, et al. Quantitative comparison of C-X-C chemokines produced by endotoxin-stimulated human alveolar macrophages. Am J Physiol (Lung Cell Mol Physiol) 1998; 19: L87-L95.

47. Strieter RM, Kunkel SL, Showell HJ, et al. Endothelial cell gene expression of a neutrophil chemotactic factor by TNF, LPS, and IL-1. Science 1989; 243: 1467-1469.

48. Strieter RM, Phan SH, Showell HJ, et al. Monokineinduced neutrophil chemotactic factor gene expression in human fibroblasts. J Biol Chem 1989; 264: $10621-$ 10626.

49. Thornton AJ, Strieter RM, Lindley I, et al. Cytokineinduced gene expression of a neutrophil chemotactic factor/interleukin-8 by human hepatocytes. $J$ Immunol 1990; 144: 2609-2613.

50. Standiford TJ, Kunkel SL, Basha MA, et al. Interleukin-8 gene expression by a pulmonary epithelial cell line: a model for cytokine networks in the lung. $J$ Clin Invest 1990; 86: 1945-1953.

51. Baggiolini M, Waits A, Kunkel SL. NAP-1/IL-8, a novel cytokine that activates neutrophils. $J$ Clin Invest 1989; 57: 2837-2841.

52. Matsushima K, Oppenheim JJ. Interleukin-8 and MCAF: novel inflammatory cytokines inducible by IL-1 and TNF. Cytokine 1991; 1: 2-13.

53. Scott P, Trinchieri G. The role of natural killer cells in host parasite interactions. Curr Opin Immunol 1995; 7: $34-40$.

54. D'Andrea A, Rengaraju M, Valiante NM, et al. Production of natural killer cell stimulatory factor (NKSF/IL-12) by peripheral blood mononuclear cells. J Exp Med 1992; 176: 1387-1398.

55. Macatonia SE, Hosken NA, Litton M, et al. Dendritic cells produce IL-12 and direct the development of Th1 cells from naive CD4+ T cells. J Immunol 1995; 154 : 5071-5079.

56. Cleveland MG, Gorham JD, Murphy TL, et al. Lipoteichoic acid preparations of gram-positive bacteria induce interleukin-12 through a CD 14independent pathway. $J$ Infect Immun 1996; 64: 1906-1912.

57. Klinman DM, Yi AK, Beaucage SL, et al. CpG motifs present in bacteria DNA rapidly induce lymphocytes to secrete interleukin-6, interleukin-12 and interferon gamma. Proc Natl Acad Sci USA 1996; 93: 2879-2883.

58. $\mathrm{D}^{\prime}$ Andrea A, Aste-Amezaga M, Valiante NM, et al. Interleukin-10 inhibits human lymphocyte IFN- $\gamma$ production by suppressing natural killer cell stimulatory factor/interleukin-12 synthesis in accessory cells. J Exp Med 1993; 178: 1041-1048.

59. D'Andrea A, Rengaraju M, Valiante NM, et al. Production of natural killer cell stimulatory factor (NKSF/IL-12) by peripheral blood mononuclear cells. J Exp Med 1992; 176: 1387-1398.

60. Cleveland MG, Gorham JD, Murphy TL, et al. Lipoteichoic acid preparations of gram-positive bacteria induce interleukin-12 through a CD14independent pathway. J Infect Immun 1996; 64: 1906-1912.

61. Klinman DM, Yi AK, Beaucage SL, et al. CpG motifs present in bacteria DNA rapidly induce lymphocytes to secrete interleukin 6, interleukin 12 and interferon gamma. Proc Natl Acad Sci USA 1996; 93: 2879-2883.

62. Sato $\mathrm{Y}$, Roman $\mathrm{M}$, Tighe $\mathrm{H}$, et al. Immunostimulatory DNA sequences necessary for effective intradermal gene immunization. Science 1996; 273: 352 354.

63. Heufler C, Koch F, Stanzl U, et al. Interleukin-12 is produced by dendritic cells and mediates Th1 development as well as IFN- $\gamma$ production by Th1 cells. Eur J Immunol 1996; 26: 659-668.

64. Greenberger MJ, Kunkel SL, Strieter RM, et al. IL-12 gene therapy protects mice in lethal Klebsiella pneumonia. J Immunol 1996; 157: 3006-3012.

65. Fiorentino DF, Zlotnik A, Mosmann TR, et al. IL-10 inhibits cytokine production by activated macrophages. J Immunol 1991; 147: 3815.

66. Gazzinelli RT, Wysocka M, Hieny $\mathrm{S}$, et al. In the absence of endogenous IL-10, mice acutely infected with Toxoplasma gondii succumb to a lethal immune 
response dependent on CD4+ $\mathrm{T}$ cells and accompanied by overproduction of IL-12, IFN-gamma and TNF-alpha. J Immunol 1996; 157: 798-805.

67. Standiford TJ, Strieter RM, Lukacs NW, Kunkel SL. Neutralization of IL-10 increases lethality in endotoxemia: Cooperative effects of macrophage inflammatory protein-2 and tumor necrosis factor. J Immunol 1995; 155: 2222-2229.

68. Banchereau J, Steinman RM. Dendritic cells and the control of immunity. Nature 1998; 392: 245-262.

69. Banchereau J, Briere F, Caux C, et al. Immunobiology of dendritic cells. Annu Rev Immunol 2000; 18: 767811.

70. Ibrabim MAA, Chain BM, Katz DR. The injured cell: the role of the dendritic cell system as a sentinel receptor pathway. Immunol Today 1995; 16: 181-186.

71. Matzinger P. Tolerance, danger and the extended family. Annu Rev Immunol 1994; 12: 991-1045.

72. Pulendran B, Lingappa J, Kennedy MK, et al. Developmental pathways of dendritic cells in vivo: distinct function, phenotype, and localization of dendritic cell subsets in FLT3 ligand-treated mice. J Immunol 1997; 159: 2222-2231.

73. Salomon B, Cohen JL, Masurier C, et al. Three populations of mouse lymph node dendritic cells with different origins and dynamics. J Immunol 1998; 160: 708-717.

74. Vremec D, Shortman K. Dendritic cell subtypes in mouse lymphoid organs. J Immunol 1997; 159: $363-$ 573.

75. Ardavin C, Wu L, Li CL, Shortman K. Thymic dendritic cells and $\mathrm{T}$ cells develop simultaneously in the thymus from a common precursor population. Nature 1993; 3: 761-763.

76. Wu L, Li CL, Shortman K, et al. Thymic dendritic cell precursors: relationship to the $\mathrm{T}$ lymphocyte lineage and phenotype of the dendritic cell progeny. $J$ Exp Med 1996; 184: 903-911.

77. Galy A, Travis M, Cen D, Chen B. Human T, B, natural killer and dendritic cells arise from a common bone marrow progenitor cell subset. Immunity 1995; 8: 459-478.

78. Inaba $\mathrm{K}$, Inaba $\mathrm{M}$, Romani $\mathrm{N}$, et al. Generation of large numbers of dendritic cells from mouse bone marrow cultures supplemented with granulocyte/ macrophage colony stimulating factor. J Exp Med 1992; 176: 1693-1702.

79. Caux C, Dezutter-Dambuyant C, Schmitt D, Banchereau J. GM-CSF and TNF-alpha cooperate in the generation of dendritic Langerhans cells. Nature 1992; 360: 258-261.

80. Sallusto F, Lansavecchia A. Efficient presentation of soluble antigen by cultured human dendritic cells is maintained by granulocyte/macrophage colonystimulating factor plus interleukin 4 and downregulated by tumor necrosis factor alpha. $J$ Exp Med 1994; 180: 83-93.

81. Romani N, Gruner S, Brong D, et al. Proliferating dendritic cell progenitors in human blood. $J$ Exp Med 1994; 180: 83-93.

82. Maraskovsky E, Brasel K, Teepe M, et al. Dramatic increase in the numbers of functionally mature dendritic cells in Flt3 ligand-treated mice: multiple dendritic cell subpopulations identified. J Exp Med 1996; 184: 1953-1962.

83. Shurin MR, Pandharipande PP, Zorina TD, et al. Flt3 ligand induces the generation of functionally active dendritic cells in mice. Cell Immunol 1997; 179: 174 184.

84. Pulendran B, Smith JL, Jenkins M, Schoenborn M, Maraskovsky E, Maliszowski CR. Prevention of peripheral tolerance by a dendritic cell growth factor: Flt3 ligand as an adjuvant. J Exp Med 1998; 188: 2075-2082.

85. Pulendran B, Smith JL, Caspray G, et al. Distinct dendritic cell subsets differentially regulate the class of immune response in vivo. Proc Natl Acad Sci USA 1999; 6: 1036-1041.

86. Pulendran B, Banchereau J, Burkeholder S, et al. Flt3-ligand and granulocyte colony-stimulating factor mobilize distinct human dendritic cell subsets in vivo. J Immunol 2000; 165: 566-572.

87. Arpinati M, Green CL, Heimfeld S, Heuser JE, Anasetti C. Granulocyte-colony stimulating factor mobilizes $\mathrm{T}$ helper 2-inducing dendritic cells. Blood 2000; 95: 2484-2490.

88. Daro E, Pulendran B, Brasel K, et al. Polyethylene glycol-modified GM-CSF expands CD11b $\mathrm{CD} 11 \mathrm{c}^{\text {high }}$, but not $\mathrm{CD} 11 \mathrm{~b}^{\text {low }} \mathrm{CD} 11 \mathrm{c}^{\text {high }}$ murine dendritic cells in vivo: a comparative analysis with Flt3 ligand. J Immunol 2000; 165: 49-58.

89. Maraskovsky M, Daro E, Roux E, et al. In vivo generation of human dendritic cell subsets by Flt3 ligand. Blood 2000; 96: 878-884.

90. Shortman K, Caux C. Dendritic cell development: Multiple pathways to nature's adjuvants. Stem Cells 1997; 15: 409-419.

91. Romani N, Gruner S, Brang D, et al. Proliferating dendritic cell progenitors in human blood. J Exp Med 1994; 180: 83-93.

92. Sallusto F, Lanzavecchia A. Efficient presentation of soluble antigen by cultured human dendritic cells is maintained by granulocyte macrophage colonystimulating factor plus interleukin 4 and downregulated by tumor necrosis factor alpha. $J$ Exp Med 1994; 179: 1109-1118.

93. Cella M, Sallusto F, Lanzavecchia A. Origin, maturation and antigen presenting function of dendritic cells. Curr Opin Immunol 1997; 9: 10-16.

94. Palucka KA, Taquet N, Sanchez-Chapuis F, Gluckman JC. Dendritic cells as the terminal stage of monocyte differentiation. J Immunol 1998; 160: 4587-4595.

95. Caux C, Vanbervliet B, Massacrier C, et al. CD 34- hematopoietic progenitors from human cord blood differentiate along two independent dendritic cell pathways in response to GM-CSF+ TNF alpha. $J$ Exp Med 1996; 184: 695-706.

96. Randolph GJ, Beaulieu S, Lebecque S, Steinman RM, Muller WA. Differentiation of monocytes into dendritic cells in a model of transendothelial trafficking. Science 1998; 282: 480-483.

97. Sozzani S, Sollusto F, Luini W, et al. Migration of dendritic cells in response to formyl peptides, C5a and a distinct set of chemokines. $J$ Immunol 1995; 155 : 3292-3295.

98. Rubbert A, Combadiere C, Ostrowski M, et al. Dendritic cells express multiple chemokine receptors used as coreceptors for HIV entry. J Immunol 1998; 160: 3933-3941.

99. Greaves DR, Wang W, Dairaghi DJ, et al. CCR6, a CC chemokine receptor that interacts with macrophage inflammatory protein 3 alpha and is highly expressed in human dendritic cells. J Exp Med 1997; 186: 837-844. 
100. Dieu MC, Vanbervliet B, Vicari A, et al. Selective recruitment of immature and mature dendritic cells by distinct chemokines expressed in different anatomic sites. J Exp Med 1998; 188: 373-386.

101. Sozzani S, Allavena P, D'Amico G, et al. Cutting edge: Differential regulation of chemokine receptors during dendritic cell maturation: a model for their trafficking properties. J Immunol 1998; 161: 1083 1086.

102. Kalinski P, Hilkens CM, Wierenga EA, Kapsenberg ML. T-cell priming by type- 1 and type- 2 polarized dendritic cells: the concept of a third signal. Immunol Today 1999; 20: 561-567.

103. Caux C, Vanbervliet B, Massacrier C, et al. B70/B7-2 is identical to CD86 and is the major functional ligand for CD28 expressed on human dendritic cells. J Exp Med 1994; 180: 1841-1847.

104. Inaba $\mathrm{K}$, Inaba $\mathrm{M}$, Witmer-Pack $\mathrm{M}$, et al. Expression of B7 costimulator molecules on mouse dendritic cells. Adv Exp Med Biol 1995; 378: 65-70.

105. Gunn MD, Tangemann K, Tam C, et al. A chemokine expressed in lymphoid high endothelial venules promotes the adhesion and chemotaxis of naïve $\mathrm{T}$ lymphocytes. Proc Natl Acad Sci USA 1998; 95: 258263.

106. Sollusto F, Schaerli P, Loetscher P, et al. Rapid and coordinated switch in chemokine receptor expression during dendritic cell maturation. Eur J Immunol 1998; 28: 2760-2769.

107. Toews GB. Pulmonary dendritic cells: sentinels of lung-associated lymphoid tissues. Am J Respir Cell Mol Biol 1991; 4: 204-205.

108. Armstrong LR, Christensen PJ, Paine R, et al. Regulation of the immunostimulatory activity of rat pulmonary dendritic cells by cell-cell interactions and cytokines. Am J Respir Cell Mol Biol 1993; 11: 682-691.

109. Christensen PJ, Armstrong LR, Fak J, et al. Regulation of rat pulmonary dendritic cell immunostimulatory activity by alveolar epithelial cell-derived GM-CSF. Am J Respir Cell Mol Biol 1995; 13: 426433.

110. Mosmann TR, Coffman RL. Th1 and Th2 cells: different patterns of lymphokine secretion lead to different functional properties. Annu Rev Immunol 1989; 7: 145-173.

111. Powrie F, Coffman RL. Cytokine regulation of $\mathrm{T}$ cell function: potential for therapeutic intervention. Immunol Today 1993; 14: 270-274.

112. Trinchieri G. Interleukin-12: a proinflammatory cytokine with immunoregulatory functions that bridge innate resistance and antigen-specific adaptive immunity. Annu Rev Immunol 1995; 13: 251-276.

113. Trinchieri G, Gerosa F. Immunoregulation by interleukin-12. J Leukocyte Biol 1996; 59: 505-511.

114. Trinchieri G. Interleukin 12: a cytokine produced by antigen-presenting cells with immunoregulatory functions in the generation of $\mathrm{T}$ helper cells type $\mathrm{I}$ and cytotoxic lymphocytes. Blood 1994; 84: 4008-4027.

115. Shu U, Kiniwa M, Wu CY, et al. Activated T cells induce interleukin-12 productin by monocytes via CD40-CD40 ligand interaction. Eur J Immunol 1995; 25: $1125-1128$.

116. Cella M, Scheidegger D, Plamer-Lehmann K, et al. Ligation of CD40 on dendritic cells triggers production of high levels of interleukin-12 and enhances $\mathrm{T}$ cell stimulatory capacity: T-T help via APC activation. J Exp Med 1996; 184: 747-752.

117. Trinchieri G. Interleukin-12: a pro-inflammatory cytokine with immunoregulatory functions that bridge innate resistance and antigen-specific adaptive immunity. Annu Rev Immunol 1995; 13: 251-276.

118. Trinchieri G, Gerosa F. Immunoregulation by interleukin-12. J Leukocyte Biol 1996; 59: 505-511.

119. Trinchieri G. Interleukin 12: a cytokine produced by antigen-presenting cells with immunoregulatory functions in the generation of $\mathrm{T}$ helper cells type 1 and cytotoxic lymphocytes. Blood 1994; 84: 4008-4027.

120. Hsieh C-S, Macatonia SE, Tripp CS, Wolf SF, O'Garra A, Murphy KM. Development of Th1 CD4+ T cells through IL-12 Produced by Listeriainduced macrophages. Science 1993; 260: 547-549.

121. Macatonia SE, Hosken NA, Litton M, et al. Dendritic cells produce IL-12 and direct the development of Th1 cells from naïve CD4+ T cells. J Immunol 1995; 154: 5071-5079.

122. Jacobson NG, Szabo SJ, Weber-Nordt RM, et al. Interleukin 12 signaling in T helper type 1 (Th1) cells involves tyrosine phosphorylation of signal transducer and activator of transcription Stat 3 and Stat4. J Exp Med 1995; 181: 1755-1762.

123. Thierfelder WE, van Deursen JM, Yamamoto K, et al. Requirement for Stat4 in interleukin-12-mediated responses of natural killer and T cells. Nature 1996; 382: $171-174$

124. O'Garra A. Cytokines induce the development of functionally heterogeneous $\mathrm{T}$ helper cell subsets. Immunity 1998; 8: 275-283.

125. Kaplan $\mathrm{MH}$, Grusby MJ. Regulation of $\mathrm{T}$ helper cell differentiation by STAT molecules. J Leuk Biol 1998; 64: 2-5.

126. Rogge L, Barberis-Maino L, Biffi M, et al. Selective expression of an interleukin-12 receptor component by human T helper 1 cells. J Exp Med 1997; 185: 825-831.

127. Szabo S, Dighe AS, Gubler U, Murphy KM. Regulation of the interleukin (IL)-12 $\beta 2$ subunit expression in developing T helper 1 (Th1) and Th2 cells. J Exp Med 1997; 185: 817-824.

128. Robinson D, Shibuya K, Mui A, et al. IGIF does not drive Th1 development, but synergizes with IL-12 for IFN- $\gamma$ production, and activates IRAK and NF- $\mathrm{KB}$. Immunity 1997; 7: 571-581.

129. Huffnagle GB, Chen GH, Curtis JL, et al. Down regulation of the afferent phase of T-cell-mediated pulmonary inflammation and immunity by a huge melanin-producing strain of Cryptococcus neoformans. J Immunol 1995; 155: 3507-3516.

130. Huffnagle GB, Toews GB, Burdick MD, et al. Afferent phase production of TNF- $\alpha$ is required for the development of protective $\mathrm{T}$ cell immunity to Cryptococcus neoformans. J Immunol 1996; 157: 4529_ 4536.

131. Huffnagle GB, Traynor TR, McDonald RA, et al. Leukocyte recruitment during pulmonary C. neoformans infection. Immunopharmacology 2000; 48: 231-236.

132. Huffnagle GB, Lipscomb M, Lovhik J, et al. The role of $\mathrm{CD} 4+$ and $\mathrm{CD} 8+\mathrm{T}$ cells in the protective inflammatory response to a pulmonary cryptococcal infection. J Leuk Biol 1994; 55: 35-42.

133. Fitch FW, McKisic MD, Lancki DW, et al. Differential regulation of murine $\mathrm{T}$ lymphocyte subsets. Annu Rev Immunol 1993; 11: 29-48.

134. Maldonado-Lopez R, De Smedt T, Michel P, et al. 
CD8 alpha+ and CD8 alpha - subclasses of dendritic cells direct the development of distinct $\mathrm{T}$ helper cells in vivo. J Exp Med 1999; 189: 587-592

135. Sousa CR, Hieny S, Scharton-Kersten T, et al. In vivo microbial stimulation induces rapid CD40 ligandindependent production of interleukin 12 by dendritic cells and their redistribution to T cell areas. J Exp Med 1997; 186: 1819-1829.

136. Maldonado-Lopez R, De Smedt T, Michel P, et al. CD8 alpha+ and CD8 alpha - subclasses of dendritic cells direct the development of distinct $\mathrm{T}$ helper cells in vivo. J Exp Med 1999; 189: 587-592.

137. Ohteki T, Fukao $\mathrm{T}$, Suzue $\mathrm{K}$, et al. Interleukin 12-dependent interferon gamma production by CD8 alpha+ lymphoid dendritic cells. J Exp Med 1999; 189: 1981-1986.

138. Ruedi C, Bachmann MF. CTL priming by CD8(+) and CD8(-) dendritic cells in vivo. Eur J Immunol 1999; 29: $3762-3767$.

139. Freeman GJ, Boussiotis VA, Anumanthan A, et al. B7-1 and B7-2 do not deliver identical costimulatory signals, since B7-2 but not B7-1 preferentially costimulates the initial production of IL-4. Immunity 1995; 2: $523-532$.

140. Bluestone JA. New Perspective of CD28-B7-mediated $\mathrm{T}$ cell costimulation. Immunity 1995; 2: 555-559.

141. Huffnagle GB, Yates JL, Lipscomb MF. Immunity to a pulmonary Cryptococcus neoformans required both CD4+ and CD8+ T cells. J Exp Med 1991; 173: 193.

142. Curtis JL, Chen G-H, Warnock ML, et al. Experimental pulmonary cryptococcosis: differences in pulmonary inflammation and lymphocyte recruitment induced by two strains of $C$. neoformans. Lab Invest 1994; 71: 113-126.

143. Huffnagle GB, Strieter RM, Standiford TJ, et al. The role of monocyte chemotactic protein-1 (MCP-1) in the recruitment of monocytes and $\mathrm{CD} 4+\mathrm{T}$ cells during a pulmonary Cryptococcus neoformans infection. J Immunol 1995; 155: 4790-4797.

144. Huffnagle GB, Strieter RM, McDonald RA, et al. Macrophage inflammatory protein-1alpha is required for a protective pulmonary inflammatory response to Cryptococcus neoformans. J Immunol 1997; 159: 318 327.

145. Mornex JF, Martinet Y, Yamauchi K, et al. Spontaneous expression of the c-sis gene and release of a pleatelet-derived growth factor-like molecule by human alveolar macrophages. J Clin Invest 1986; 78 : $61-66$.

146. Assoian RK, Fleudelys GE, Stevensen HC, et al. Expression and secretion of type beta transforming growth factor by activated human macrophages. Cell 1988; 53: 285-293.

147. Henke C, Marineili W, Jessurn J, et al. Macrophage production of basic fibroblast growth factor in the fibroproliferative disorder of alveolar fibrosis after lung injury. Am J Pathol 1993; 143: 1189-1199.

148. Madtes DK, Klima LD, Rubenfeld G, et al. Elevated transforming growth factor-alpha levels in bronchoalveolar lavage fluid in patients with acute respiratory distress syndrome. Am J Respir Crit Care Med 1998; 158: 424-430.

149. Kheradmand F, Folkesson HG, Shum L, et al. Transforming growth factor-alpha enhances alveolar epithelial cell repair in a new in vitro model. Am J Physiol 1994; 267: L728-L738.

150. Rose R, Raines EW, Bowen-Pope DF. The biology of platelet-derived growth factor. Cell 1986; 46: 155-169.

151. Moses HL, Yang EL, Pietenpol JA. TGFb stimulation and inhibition of cell proliferation: new mechanistic insights. Cell 1990; 63: 245-247.

152. Moore BB, Coffey MJ, Christensen PJ, et al. GM$\mathrm{CSF}$ regulates bleomycin-induced pulmonary fibrosis via a prostaglandin-dependent mechanism. J Immunol 2000; 165: 4032-4039.

153. Christensen PJ, Bailie MB, Goodman RE, et al. Role of diminished epithelial cell GM-CSF in the pathogenesis of bleomycin-induced pulmonary fibrosis. $\mathrm{Am}$ J Physiol (Lung Cell Mol Physiol) 2000; 279: L487L495.

154. Moore BB, Christensen PJ, Wilke C, et al. Fluorescein isothiocyanate-induced pulmonary fibrosis is regulated by monocyte chemoattractant protein-1 and CC chemokine receptor-2. Chest 2001; (In press).

155. Strieter RM, Polverini PJ, Kunkel SL, et al. The functional role of the ELR motif in CXC chemokine mediated angiogenesis. J Biol Chem 1995; 270: 2734827357.

156. Cohen IR. Tending Adams garden: evolving the cognitive immune self: London, Academic Press, 2000; pp. 183-185. 